\title{
A importância do mapa de risco para a prevenção de acidentes de trabalho em cozinhas/copas de hospitais do interior do Rio Grande do Sul/RS
}

Aline Sarturi Ponte ${ }^{1}$ Maria Auracélia Marchi Ribas ${ }^{2}$ Vanessa Medeiros Pinto ${ }^{3}$

RESUMO

Este artigo apresenta um relato de atividades curriculares na atenção à saúde do trabalhador. Este estudo teve como objetivo apresentar os principais riscos aos quais estão expostos os funcionários da cozinha/copa de hospitais do interior do Rio Grande do Sul/RS. Este estudo trata-se de uma observação científica, classificada como uma observação de campo, de duas práticas de Estágio Curricular Supervisionado em Terapia Ocupacional I e II, do curso de Terapia Ocupacional do Centro Universitário Franciscano - UNIFRA. Desenvolvidas na instituição "A" período de agosto a dezembro de 2011 e na instituição " $B$ " no período de março a julho de 2012. A partir deste estudo observou-se quanto é importante respeitar o trabalhador em sua maneira de elaborar e executar o seu trabalho, onde cada um na sua subjetividade tem características próprias de execução da atividade laboral, podendo se apropriar do seu fazer com dignidade, prazer e autonomia.

Descritores: Cozinha; Hospital; Mapa de Risco; Terapia Ocupacional; Trabalho.

\section{The importance of risk map for the prevention of accidents in cuisines/scullery hospitals interior of Rio Grande do Sul/RS}

\begin{abstract}
This article presents an account of curricular activities in the health care worker. This study aims to present the main risks to which employees are exposed kitchen/ scullery area hospitals in the interior of Rio Grande do Sul/RS. This study deals with a scientific observation, classified as a field observation of two practices Supervised Curricular Training in Occupational Therapy I and II, the course of Occupational Therapy Centro Universitário Franciscano - UNIFRA. Developed at the institution " $A$ " from August to December 2011 and the institution " $B$ " in period March to July 2012. From this study was observed on the important respect the worker on his way to prepare and perform their work, where everyone in his subjectivity has characteristics of the implementation of labor activity and can take ownership of their cause dignity, pleasure and autonomy.
\end{abstract}

Descriptors: Cooking; Hospital; Risk Map; Occupational Therapy; Work.

\footnotetext{
${ }^{1}$ Mestranda em Distúrbios da Comunicação Humana pela Universidade Federal de Santa Maria (UFSM), Santa Maria, RS, Brasil.

2 Terapeuta Ocupacional pelo Centro Universitário Franciscano (UNIFRA), Santa Maria, RS, Brasil.

${ }^{3}$ Mestre em Reabilitação e Inclusão pelo Centro Universitário do IPA (IPA), Porto Alegre, RS, Brasil.
} 


\section{Introdução}

O estudo discutido neste trabalho é resultado de práticas de Estágio Curricular Supervisionado em Terapia Ocupacional I e II, do curso de Terapia Ocupacional do Centro Universitário Franciscano - UNIFRA. Durante estas atividades curriculares os acadêmicos realizam práticas de atenção a saúde do trabalhador, como ginástica laboral, algumas orientações referentes à prevenção de doenças ocupacionais e acidentes no local de trabalho.

No decorrer das atividades observou-se no ambiente de trabalho algumas irregularidades, para identificar estas no decorrer da discussão será utilizado um o instrumento mapa de risco. As avaliações de risco constituem um conjunto de procedimentos com o objetivo de estimar o potencial de danos à saúde ocasionados pela exposição de indivíduos a agentes ambientais ${ }^{1}$.

A terapia ocupacional tem como objetivo na saúde do trabalhador entender e averiguar as atividades nas quais o sujeito envolve-se, assim compreendendo a relação indivíduo - trabalho e os aspectos que circundam esta relação, estes são: aspectos cognitivos, físicos e sociais ${ }^{2}$. Frente a estes objetivos citados acima o terapeuta ocupacional desenvolve práticas em saúde do trabalhador com intuito de prevenção, tratamento, reabilitação e criando novas condições de trabalho para aquele trabalhador acometido por alguma patologia ${ }^{3}$. No ambiente de trabalho o terapeuta ocupacional visa a eliminar de barreiras e adequar o espaço, assim tornado mais adequado e confortável, facilitando o manejo do profissional em seu posto de trabalho ${ }^{4}$.

Este estudo teve como objetivo apresentar os principais riscos aos quais estão expostos os funcionários da cozinha/ copa de hospitais do interior do Rio Grande do Sul/RS.

\section{Metodologia}

Este estudo trata-se de um estudo descritivos de caráter qualitativo. A coleta de dados ocorreu em dois momentos, na instituição " $A$ " período de agosto a dezembro de 2011 e na instituição " $B$ " no período de março a julho de 2012, Neste período as acadêmicas realizavam atividades de ginástica laboral com os funcionários da cozinha/copa das instituições.

A Ginastica Laboral é um dos instrumentos mais utilizados nos Brasil atualmente para a intervenção no trabalho. Este prática tem como objetivo a prevenção de doenças e a promoção da saúde 5 . "A GL tem características de preparação muscular para o trabalho, pausa, correção postural ou relaxamento muscular"5 (p. 132).

A partir das atividades desenvolvidas no local traçou-se um mapa de risco para a cozinha/copa das instituições $A$ e $B$. Para a elaboração do mapa de risco observou-se os riscos existentes no local, instrumentos de trabalho, disposição e largura das portas, disposição das janelas, materiais de trabalho, extintores e das placas sinalizadoras, se os funcionários faziam uso dos Equipamentos de Proteção individual (EPIs) e se existe organização no local de trabalho.

Para complementar a coleta de dados os funcionários foram convidados a responder voluntariamente a um questionário, este instrumento é contemplado com as seguintes observações: idade, sexo, principais queixas de saúde, local de trabalho, jornada de trabalho e turno, treinamento profissional, atividade exercida, ausenta-se muito do trabalho, instrumentos de trabalho, apresenta alguma patologia, acidente que ocorreram no local de trabalho, sente-se exposto a algum risco e a função que exerce trás algum risco a sua saúde ocupacional.

O mapa de risco é obrigação das Comissões Internas de Prevenção de Acidentes (CIPA), este é uma representação gráfica dos riscos de acidentes nos diversos locais de trabalho, inerentes ou não ao processo produtivo, devendo ser afixado em locais acessíveis e de fácil visualização no ambiente de trabalho, com a finalidade de informar e orientar todos os que ali atuam e outros que, eventualmente, transitem pelo local. Segundo a Portaria 25, este instrumento deve ser elaborado pela CIPA, com a participação dos trabalhadores envolvidos no processo produtivo e com a orientação do Serviço Especializado em Engenharia de Segurança e Medicina do Trabalho (SESMT) do estabelecimento, quando houver. O mapa de riscos é representado graficamente, através de círculos de cores e tamanhos proporcionalmente diferentes (riscos pequeno médio e grande), sobre o Lay-Out da empresa ${ }^{6}$.

Este instrumento foi criado através da Portaria n 05 em 17 de agosto de 1992 tratando da obrigatoriedade, por parte de todas as empresas, da "representação gráfica dos riscos existentes nos diversos locais de trabalho", e faz parte das Normas Regulamentadoras (NR), NR-09. Posteriormente o Mapa de Risco passou a constar como anexo IV da NR-05, por meio da Portaria $n^{0} 25$ de 29 de dezembro de $1994^{7}$. 


\section{Resultados e discussões}

Para realizar as atividades de ginástica laboral e as observações junto aos funcionários da cozinha/copa os acadêmicos reuniram-se com as nutricionistas responsáveis pela administração dos ambientes e pediram autorização para o desenvolvimento de tais práticas.

Atualmente a saúde ocupacional tem enfrentado grandes desafios. Estando diante do encontro de diversas situações advindas do mundo do trabalho, já que é no trabalho que passamos a maior parte de nossas vidas, os reflexos das condições de trabalho irão refletir de forma acentuada sobre o nosso bem estar mesmo fora da jornada de trabalho8.

No hospital " $A$ " os funcionários que realizavam as práticas de ginástica laboral eram apenas os que estavam no local de trabalho durante a atividade. O qual observou-se uma predominância de funcionários do sexo feminino, a jornada de trabalho dos funcionário é de seis horas diárias, organizada em três turnos, havendo uma escala diferenciada nos finais de semana, esta com turnos de doze horas. Outro fator a ser considerado são as condições organizacionais muitas vezes exigidas pela empresa levam a uma representação mental diferenciada a cada dia (novas preparações, imprevisibilidade, novas pressões temporais, etc), esta nem sempre previstas na fase do planejamento, leva a uma diminuição da produtividade e um estresse desnecessário aos funcionários ${ }^{9}$. 0 ambiente de trabalho observado é a cozinha/copa.

Durante as atividades de ginástica laboral os funcionários do hospital " $A$ " queixaram-se de dores na coluna na região cervical e lombar principalmente, os membros inferiores e superiores também foram citados. As lesões do sistema músculoesquelético, particularmente, as algias vertebrais, são internacionalmente reconhecidas como um risco ocupacional entre os trabalhadores 9 . Movimentos repetitivos são muito comuns devido ao tipo de atividades desenvolvidas. 0 corte de alguns vegetais e a fritura de alimentos exige que o operador permaneça em pé, estático, com o pescoço flexionado durante longo período de tempo ${ }^{10}$, e esta posição acaba por gerar dores e fadiga muscular.

Os acidentes de trabalho mais observados nesta instituição foram pequenos e médios ferimentos comfacas e apresentam em graus leves as queimaduras, ocorrem geralmente por contato com vapores e líquido em alta temperatura, estas também foram de grau leve ( $\left(1^{\circ} \mathrm{grau}\right)$. Os afastamentos do trabalho não são muito frequentes no grupo de funcionários.

No hospital "A", a copa e a cozinha encontram-se em um mesmo ambiente o local não é muito arejado. Para diminuir o contato com vapor emitidos pelo processo de cozimento este local conta com um aparelho depurador de ar instalado sob o fogão. Este equipamento tem a função de sugar os vapores emitidos pelo processo de cozimento dos alimentos de jogá-los para fora do ambiente. Estudos relacionados demonstraram que as condições físicas e ambientais inadequadas em Unidades de Alimentação e Nutrição, onde os funcionários são expostos a problemas como espaço reduzido, temperatura e umidade elevadas, movimentos repetitivos, levantamento de peso excessivo, permanência por períodos prolongados na postura em pé e modificação constante de procedimentos ${ }^{11}$.

Este ambiente é aparado apenas por uma porta de acesso, encontra-se sinalizada, com largura de 1,20m e sua abertura é para dentro do local de trabalho, é o único meio de entrada e saída do ambiente em alguns momentos ocorrem transtornos no momento de circulação dos carrinhos com alimentos. Em caso de algum acidente a porta é a única via de saída dos funcionários. Segundo a norma de segurança NR-23, a largura mínima das aberturas de saída deverá ser de 1,20m; e não deverão abrir para o interior do local de trabalho; as aberturas, saídas e vias de passagem devem ser claramente assinaladas por meio de placas ou sinais luminosos, indicando a direção da saída. Quanto às portas de entrada saída ou de emergência de um estabelecimento ou local de trabalho, não poderá ser fechada a chave, aferrolhada ou presa durante as horas de trabalho ${ }^{12}$.

Já na instituição hospitalar " $B$ " o local é dividido em vários ambientes são estes cozinha, copa, administração nutricional, dispensa de alimentos não perecíveis, dispensa de alimentos perecíveis, câmara fria, sala de lava louças e preparação das dietas líquidas, depósito de materiais de limpeza, sala de armários com banheiros reservada para o descanso dos funcionários.

Os funcionários que participavam das práticas de ginástica laboral nesta instituição eram apenas os que estavam em local de trabalho, observou-se uma predominância do sexo feminino, havendo somente um funcionário do sexo masculino. A jornada de trabalho é de seis horas diárias, havendo uma escala especial para os finais de semana, esta é organizada previamente em turnos de doze horas, ocorre também uma inversão de turnos todas as semanas, os funcionários que em uma determinada semana trabalham pela manhã na outra eles irão trabalhar à tarde.

Durante a realização das atividades de ginástica laboral os funcionários do hospital " $B$ " não queixaram-se de dores as atividades propostas eram realizadas no próprio ambiente de trabalho. $O$ exercício de ginástica laboral pode ser 
preparatório e compensatório, consistindo em exercícios específicos, realizados no próprio local de trabalho, atuando de forma preventiva e terapêutica. Leve e de curta duração, esta prática visa a diminuir o número de acidentes de trabalho, prevenir doenças originadas por traumas cumulativos, prevenir a fadiga muscular, corrigir vícios posturais, aumentar a disposição do funcionário, ao iniciar e retornar ao trabalho, promover maior integração no ambiente de trabalho ${ }^{13}$. No ambiente de uma cozinha hospitalar os funcionários são expostos a vários fatores de riscos ocupacionais, segundo NR 5 do Ministério do Trabalho e Emprego. Dentre estes riscos podemos citar: ruídos excessivos, grande umidade e calor, esforço físico intenso, postura inadequada, controle rígido da produtividade, levantamento e transporte de peso, jornadas de trabalho prolongadas, monotonia e repetitividade de funções, dentre outras ${ }^{12}$.

Relacionado aos acidenteis de trabalho, esses não são frequentes, não sendo mencionados pelos funcionários durante as práticas de ginástica laboral. Este ambiente de trabalho apresentam inúmeros riscos que relacionam-se com as condições inseguras, equipamento defeituoso, falta de protetores, iluminação e ventilação inadequada, falta de Equipamentos de Proteção Individual (EPIs) adequados, além de atos inseguros, negligentes, excesso de segurança, confiança, falta de supervisão, falta de cooperação e indiferença quanto à segurança ${ }^{14}$.

Como já citado acima, o local da cozinha é dividido em vários ambientes, são todos amplos e arejados. A cozinha em sua parede externa apresenta varias janelas. $O$ ambiente não conta com presença de aparelhos exaustores para auxiliar na captura dos vapores emitidos pela ação do processo de cozimento dos alimentos. O local está amparado por três portas, uma dá acesso a área externa do hospital, esta porta é utilizada regularmente para a carga de descarga de mantimentos, é uma porta que abre em folha e apresenta 2,00m de largura, a porta que dá acesso ao refeitório apresenta uma largura de 1,20m e a terceira porta que dá acesso ao corredor tem largura de 0,90m, estas estão bem localizadas e sinalizadas com luzes de emergência, com um simples toque na maçaneta as portas abrem-se.

No decorrer das observações identificaram-se riscos que poderiam interferir no desenvolvimento da atividade de trabalho, e as consequências dessa interferência seriam as doenças ocupacionais. Os riscos apontados pelas acadêmicas são riscos de acidentes, ergonômicos, físicos, químicos e biológicos. As condições de trabalho abrangem aspectos relacionados ao levantamento, transpor-te e descarga de materiais, ao mobiliário, aos equipamentos e às condições ambientais do posto de trabalho, e à própria organização do trabalho ${ }^{12}$.

Nos riscos de acidente estão especificados os seguintes exemplos: arranjo físico inadequado, iluminação inadequada, incêndio e explosões, eletricidade, maquinas e equipamentos sem proteção, quedas e animais peçonhentos ${ }^{15}$. Os riscos de acidentes decorrentes da utilização de facas podem estar associados à iluminação e estrutura físicas inadequadas, as queimaduras também ocorrem pela exposição dos funcionários ao calor emitido pelo fogão. Os riscos de acidentes de trabalho são influenciados pelas condições de trabalho, os acidentes ocorrem por um conjunto de fatores composto pelas exigências da função, organização, execução, remuneração e ambiente ocupacional, capazes de determinar a conduta do trabalhador. As consequências do estado físico e psicológico do trabalhador são: satisfação, conforto, carga de trabalho, fadiga, estresse, doenças e acidentes de trabalho ${ }^{16}$.

Os riscos ergonômicos compreendem os seguintes fatores, levantamento e transporte manual de peso, monotonia, repetitividade, responsabilidade, ritmo excessivo, postura inadequada de trabalho, trabalhos em turnos, etc ${ }^{15}$. As posturas necessárias para a realização das tarefas neste posto de trabalho é em alguns momentos uma postura estática em pé esta exige que a região cervical permaneça flexionada durante um longo espaço de tempo, as posturas dinâmicas também são adotadas neste local de trabalho, a postura ereta e com os membros superiores elevamos, foram às principais posturas observadas no ambiente. A postura refere-se à posição do corpo no espaço e podem modificar-se várias vezes durante um determinado movimento. Portanto a postura e o movimento estão completamente associados. Quando ocorre um desconforto, seja ele pela compressão articular, tensão ligamentar, ou contração muscular, uma nova postura é solicitada ${ }^{17}$. 
Figura 1 - Mapa de Risco da Cozinha/Copa da Instituição Hospitalar "A".

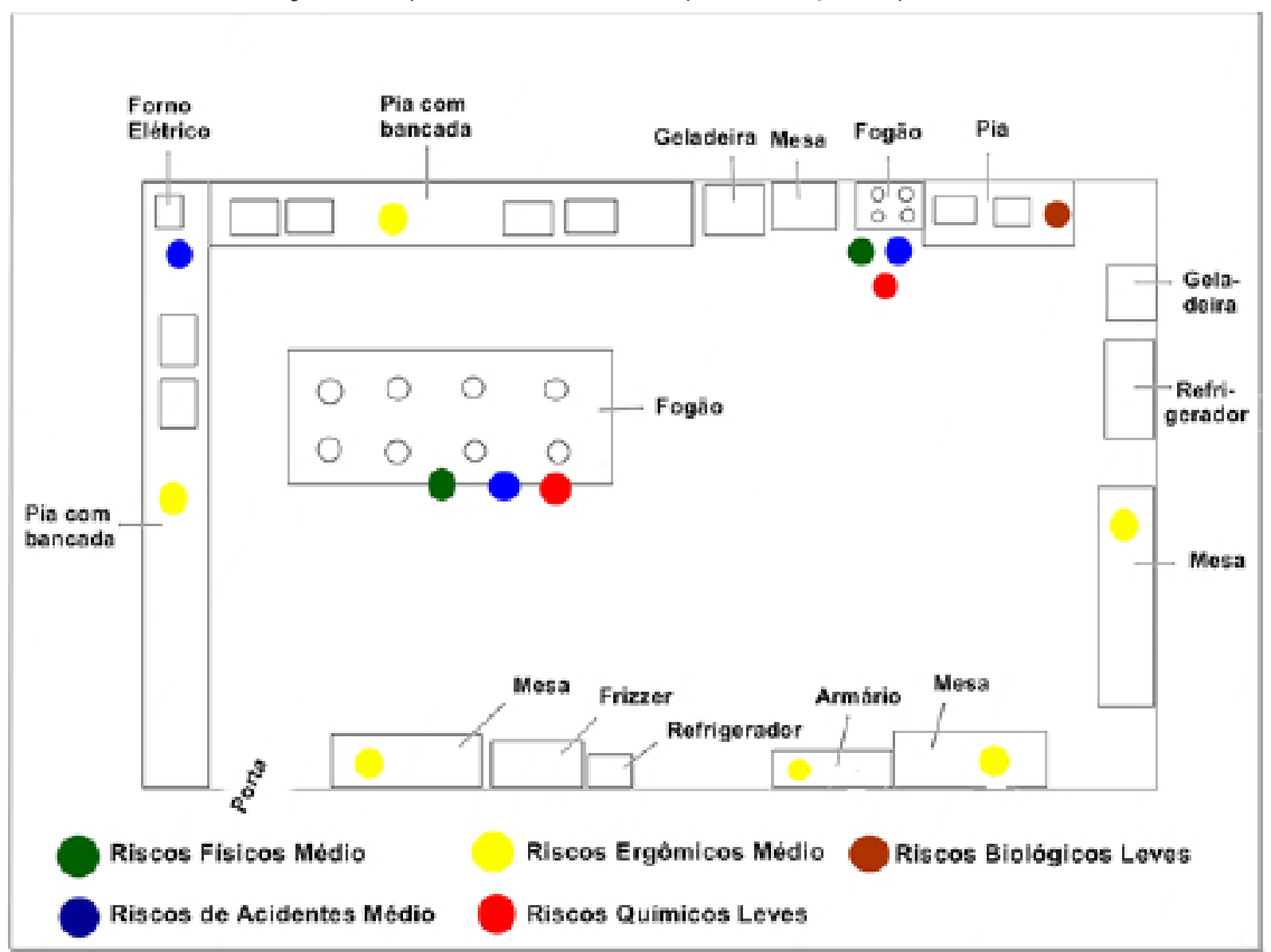

Fonte: Elaborado pelas autoras a partir NR-9 e NR-05.

Os fatores que contemplam os riscos físicos são: ruídos, calor, frio, pressão, umidade, radiação ionizante e não ionizante, vibrações, etc ${ }^{15}$. Durante a jornada de trabalho os funcionários de uma cozinha expõem-se a calor emitido pelo processo de cozimento, ao frio quando se tem que adentrar em uma câmara fria, aos ruídos emitidos pelos eletrodomésticos que fazem parte deste ambiente, estas variações de informações podem causar estresse e desconforto aos funcionários. Os fatores ambientais de natureza física, tais como ruídos, vibrações, iluminação, pressão, entre outros podem ocasionar desconforto, aumentando assim, o risco de acidentes e afetando a saúde. Outros fatores ambientais que prejudicam a saúde do trabalhado são estes radiação e poluição microbiológica. E menciona três maneiras de diminuir estes riscos, que são amenizar a emissão de poluentes, isolar as fontes emissoras e utilizar EPIs ${ }^{18}$.

Os riscos biológicos e químicos encontram-se relacionados, pois os indicadores biológicos de exposições ambientais aos riscos de origem química nos locais de trabalho, que servem de base para as avaliações de risco e vigilância em saúde ${ }^{19}$. Os riscos químicos com, poeira, fumo, gazes, vapores, névoas, neblinas, etc. Já os riscos biológicos este lista como sendo provenientes de fungos, vírus, parasitas, bactérias, protozoários, insetos, etc ${ }^{15}$.

Os funcionários da copa entram em contato com as bandejas que retornam dos leitos, assim realizando a sua higienização, mesmo este funcionários utilizando os EPIs estes podem no decorrer da atividade laboral entrar em contato com agente biológicos provenientes da patologia dos pacientes ou com agentes químicos oriundos das medicações administradas nestes. $\mathrm{O}$ ambiente hospitalar como um local insalubre, o qual apresenta pessoas com distintas patologias infectocontagiosas, expondo os funcionários a contato com materiais infectados, oferecendo aos funcionários riscos de acidentes e doenças decorrentes do ambiente de trabalho ${ }^{20}$. Os fatores biológicos os quais estes funcionários se expõem são provenientes da inalação, ingestão ou dermo-absorção de compostos químicos presentes no meio ambiente, muitos dos quais são indicadores de propriedades teratogênicas, mutagênicas e carcinógenas para humanos ${ }^{21}$. 
Figura 2 - Mapa de Risco da Cozinha/Copa da Instituição Hospitalar "B".



Fonte: Elaborado pelas autoras a partir NR-9 e NR-05.

As avaliações referentes a riscos nos postos de trabalho vêm intensificando-se com o passar do tempo, pois estes cuidados com a saúde do trabalhador resultam na diminuição de prejuízos tanto para trabalhadores quanto para empresas. A promoção da saúde é resultado de um dia-a-dia saudável, de tal modo que o individuo possa desfrutar o melhor que a vida tem a oferecer, seja da forma como ele se alimenta ou como ele lida com o estresse ${ }^{20}$. Este autor aborda a importância da terapia ocupacional, pois este profissional tem um olhar diferenciado frente à saúde e o sujeito e também, utiliza-se do fazer humano como instrumento de tratamento, ou seja, as atividades da vida diária (AVD) e as atividades instrumentais de vida diária (AIVD) do sujeito são elementos norteadores para o terapeuta ocupacional traçar 0 seu plano de tratamento junto às necessidades do paciente ${ }^{21}$. A pesquisa sobre os procedimentos característicos do trabalho nos permite repensar nossas posições, fazer novas propostas e reconhecer não apenas os problemas, mas também as possibilidades de prevenção de doenças ocupacionais.

\section{Considerações finais}

A partir deste estudo observou-se quanto é importante respeitar o trabalhador em sua maneira de elaborar e executar 0 seu trabalho, onde cada um na sua subjetividade tem características próprias de execução da atividade laboral, podendo se apropriar do seu fazer com dignidade, prazer e autonomia.

A prática de ginastica laboral observou-se que esta atividade proporciona um momento de autocuidado, prevenção e descontração. A ginastica laboral pode tornar-se um momento educativo, pois a partir desta prática o terapeuta proporciona os participantes esclarecimentos sobre algumas posturas incorretas, as quais devem evitar, eram sugeridas adaptações que visavam a melhora nas posturas no posto de trabalho e minimizariam os desconfortos osteomusculares.

O mapa de risco tornou-se um grande aliado para as terapeutas, pois contribuiu para uma melhor visualização do local e da dinâmica de trabalho, assim como a intensidade (leve, moderada ou grave) dos diferentes riscos aos quais estavam expostos os trabalhadores da cozinha/copa das instituições. Tal compreensão possibilitou as terapeutas traçar planos terapêuticos que proporcionassem um cuidado as reais necessidades de saúde apresentadas pelos trabalhadores, assim como momentos educativos, melhoras no posto de trabalho (adaptações). 
Conclui-se que, a Terapia Ocupacional poderá intervir junto a este sujeito como um agente facilitador, atuando na significação e organização do trabalho, através de orientações preventivas, de promoção da saúde para que o mesmo possa realizar seu trabalho com qualidade de vida.

\section{Referências bibliográficas}

1. METELLO FC, VALENTE GSC. The importance of biosecurity measures to prevent workplace accidents through the identification of biohazards in the risk map. R. pesq.: cuid. fundam. v. 4, n. 3, p. 2338-48. 2012.

2. WATANABE M, GONÇALVES R M. A. Relação Conceitual entre Terapia Ocupacional e Ergonomia. In: LANCMAN S. Saúde, Trabalho e Terapia Ocupacional. - São Paulo: Roca, 2004.

3. TAKAHASHI MABC, SIMONELLI AP, SOUSA HP, MENDES RWB, ALVARENGA MVA. Programa de reabilitação profissional para trabalhadores com incapacidades por LER/DORT: relato de experiência do Cerest-Piracicaba, SP. Rev. bras. saúde ocup. v.35 n.121, p. 100-111, 2010.

4. SUMSION, T. Considerações Ambientais. In: SUMSION, T. Práticas baseadas no cliente na terapia ocupacional: guia para implementação. - São Paulo: Roca, 2003.

5. GRANDE AJ, LOCH MR, GUARIDO EA, COSTA JBY, GRANDE GC. REICHERT FF. Comportamentos Relacionados à Saúde entre Participantes e não Participantes da Ginástica Laboral. Rev Bras Cineantropom Desempenho Hum. v. 13, n 2, p. 131-137. 2011.

6. BRASIL. Portaria Nº 25, de 29.12.94, do Secretário de Segurança e Saúde no Trabalho: Norma Regulamentadora NR - 9. Brasília, DF: Câmara dos Deputados, Edições Câmara, 1994.

7. MATTOS UAO, FREITAS NBB. Mapa de Risco no Brasil: as Limitações da Aplicabilidade de um modelo Operário. Cad. Saúde Públ., Rio de Janeiro, v. 10, n. 2, p. 251-58. 1994.

8. SANTOS JB. Programa de exercício físico na empresa. Tese (Doutorado em Educação Física) - Universidade Federal de Santa Catarina, 2003.

9. SALLES DMR, COSTA ISA. Representações do trabalho: estudo sobre confinamento na indústria petrolífera. Rev. adm. empres. v. 53, n. 3, p. 230-42 2013.

10. ALENCAR MCB, SCHULTZE VM, SOUZA SD. Distúrbios osteomusculares e o trabalho dos que cuidam de idosos institucionalizados. Fisioter. mov. v.23, n.1, p. 63-72, 2010.

11. MATOS CH, PROENÇA RP. C. Condições de trabalho e estado nutricional de operadores do setor de alimentação coletiva: um estudo de caso. Rev. Nutr. Campinas, v. 16, n. 4, p. 493-502. 2003.

12. COLARES LGT, FREITAS CM. Processo de trabalho e saúde de trabalhadores de uma unidade de alimentação e nutrição: entre a prescrição e o real do trabalho. Cad. Saúde Pública, Rio de Janeiro, v. 23, n.12, p. 3011-3020, dez, 2007. 13. MACEDO NMMN, GADELHA MA. Análise das Normas de Segurança e Estrutura Física: Estudo de Caso de uma Creche Comunitária do Município de Fortaleza - CE. XXX Encontro Nacional de Engenharia de Produção. Maturidades e Desafios da Engenharia de Produção: competitividade das empresas, condições de trabalho, meio ambiente. São Carlos, São Paulo, Brasil, 12 a 15 de outubro de 2010.

14. GRANDE AJ, SILVA V, MANZATTO L, ROCHA TBX, MARTINS GCM, JUNIOR GBV. Comparison of worker's health promotion interventions: cluster randomized controlled trial. Rev. bras. cineantropom. desempenho hum. v.15, n.1, 2013. 15. PROCHNOW A, MAGNAGO TSBS, TAVARES JP, BECK CLC, SILVA RM, GRECO PBT. Perfil dos acidentes de trabalho publicados em estudos brasileiros. Revista. Saúde v. 37, n. 1, p. 77-90, 2011.

16. BRASIL, L. A. D. Dicas de Prevenção de Acidentes e Doenças no Trabalho: SESI - SEBRAE Saúde e Segurança no Trabalho: Micro e Pequenas Empresas/Luiz Augusto Damasceno Brasil (org.). - Brasília: SESI-DN, 2005.

17. MARTENDAL L. SANTOS KC. Adoecimento Cardíaco em um Trabalhador da Saúde. Psicol. Argum. out./dez., 26(55), 281-292. 2008.

18. ISOSAKI M, CARDOSO E, GLINA DMR, ALVES ACDC, ROCHA LER. Prevalência de sintomas osteomusculares entre trabalhadores de um Serviço de Nutrição Hospitalar em São Paulo, SP. Rev. bras. Saúde ocup., São Paulo, 36 (124): 238-246, 2011.

19. SULZBACHER E, FONTANA RT. Concepções da equipe de enfermagem sobre a exposição a riscos físicos e químicos no ambiente hospitalar. Rev. bras. enferm. [online]. vol.66, n.1, 2013. 
20. WEERDMEESTER JDB. Ergonomia Prática. São Paulo: Edgard Blucher LTDA, 2001.

21. NISHIDE, V; M; BENATTI, M. C. C; ALEXANDRE, N. M. C. Ocorrência de Acidente do Trabalho em uma Unidade de Terapia Intensiva. Rev Latino-am Enfermagem .12(2):204-11. 2004

22. OLIVEIRA, A. J. Terapia Ocupacional: perspectiva para educação em saúde do trabalhador. In: LANCMAM, S. Saúde, Trabalho e Terapia Ocupacional. São Paulo: Roca, 2004.

\section{Aline Sarturi Ponte}

Endereço para correspondência - Venâncio Aires, 1638, apto 4. Bairro Bom fim, CEP 97010-002, Santa Maria, RS, Brasil. E-mail: alinesarturi@hotmail.com

Lattes: http://lattes.cnpq.br/8576659601127889

Maria Auracélia Marchi Ribas - marchiribas@bol.com.br

Vanessa Medeiros Pinto - nessa_mpinto@hotmail.com

Enviado em 13 de janeiro de 2014.

Publicado em 09 de outubro de 2014. 